\title{
Cyberbullying among students with intellectual and developmental disability in special education settings
}

\author{
ROBERT DIDDEN ${ }^{1}$, RON H. J. SCHOLTE ${ }^{1}$, HUBERT KORZILIUS ${ }^{1}$, \\ JAN M. H. DE MOOR ${ }^{1}$, ANNE VERMEULEN ${ }^{1}$, MARK O'REILLY $^{2}$, \\ RUSSELL LANG ${ }^{3}$, \& GIULIO E. LANCIONI ${ }^{4}$ \\ ${ }^{1}$ Behavioural Science Institute, Radboud University Nijmegen, The Netherlands, ${ }^{2}$ The Meadows Center for Preventing \\ Educational Risk, The University of Texas at Austin, USA, ${ }^{3}$ University of California at Santa Barbara, USA, and \\ ${ }^{4}$ Psychology Department, University of Bari, Italy
}

(Received 10 April 2009; accepted 14 April 2009)

\begin{abstract}
Objective: To explore the types, prevalence and associated variables of cyberbullying among students with intellectual and developmental disability attending special education settings.

Methods: Students $(n=114)$ with intellectual and developmental disability who were between $12-19$ years of age completed a questionnaire containing questions related to bullying and victimization via the internet and cellphones. Other questions concerned sociodemographic characteristics (IQ, age, gender, diagnosis), self-esteem and depressive feelings.

Results: Between $4-9 \%$ of students reported bullying or victimization of bullying at least once a week. Significant associations were found between cyberbullying and IQ, frequency of computer usage and self-esteem and depressive feelings. No associations were found between cyberbullying and age and gender.

Conclusions: Cyberbullying is prevalent among students with intellectual and developmental disability in special education settings. Programmes should be developed to deal with this issue in which students, teachers and parents work together.
\end{abstract}

Keywords: Bullying, internet, cellphone, special education, youth, intellectual and developmental disability

\section{Introduction}

Bullying is a common feature among students who attend regular classrooms. Bullying may be defined as a negative intentional action aimed at causing physical and/or psychological harm against one or more students, who are weaker and unable to defend themselves. These negative actions are carried out repeatedly and over time [1]. An important characteristic of bullying is that it implies an imbalance of power between bully and victim $[1,2]$. Being a victim of bullying or aggression from peers can disrupt adolescents' emotional and social development. Victims often end up having lost their self-esteem, which can result in socialemotional difficulties $[1,3]$. Depression, underachievement and belief that they deserve to be bullied are other negative consequences of being a victim [1].

Several studies have shown that the prevalence of bullying is related to other variables such as gender, although these studies show mixed results. Boys and girls use different bully strategies, in that boys are more likely to engage in physical or direct verbal bullying than girls [4]. Girls more often use indirect forms of bullying, which are characterized by psychological attacks such as humiliation and/or manipulation of relationships.

In studies on bullying a distinction is often made between bully, victim and bully/victim. A victim usually shows higher levels of internalizing symptoms and depressive tendencies then the other types [5]. According to Olweus [1], victims of bullying are physically weaker, have fewer friends and exhibit more depression and anxiety than victims, bully/ victims and non-involved children. Bullies, on the other hand, seem to make friends with greater ease and have larger peer groups. Results of other studies indicate that bullies have higher rates of problem behaviours and have a more negative perception of the school climate than the other types [5]. Bully/victims seem to be the group with most 
maladaptive characteristics. These children are both aggressively reactive and anxious [1]. They have been shown to score higher on both externalizing and internalizing behaviour than the other groups [5].

Bullying may occur in traditional and electronic forms. Electronic forms of bullying are also referred to as cyberbullying. This type of bullying can be defined as an aggressive, intentional act carried out by a group or individual, using electronic forms of contact, repeatedly and over time against a victim who can not easily defend itself [6].

Studies on cyberbullying have been rarely published yet. In a Dutch study, prevalence of cyberbullying and its relation to social well-being was in children between 11-15 years old. Results show that $17 \%$ of children have been harassed online once a month on average, while 3\% experience this every week [7]. A small number of studies on the relationship between gender and type and prevalence of cyberbullying have appeared. Concerning gender differences in cyberbullying there are contradictory results. Children in the age range of 8-10 years old are less involved in cyberbullying than children from 14-15 years old [8,9]. According to Van den Eijnden et al. [7], there are a number of risk factors of becoming a victim of cyberbullies. First, the frequency with which a child often bullies online is important. When a child bullies online the chance of becoming a victim as well is relatively large. Secondly, the frequency with which someone uses chatsites, for example MSN messenger, plays a role. Being in online contact with strangers and the use of weblogs are risk factors as well. Other characteristics such as being fat, thin, big, small or being a member of an ethnic minority group are no risk factors for being a victim of cyberbullying [10]. Children who are being bullied in the traditional form seem to spend more time behind the computer than children who aren't victims. Spending much time behind the computer might increase the chance of being cyberbullied as well. According to Van den Eijnden et al. [7], youth who have been bullied by electronic tools experience more depressive feelings, feelings of loneliness and have a more negative self-concept than adolescents who have not been cyberbullied.

Only a few studies have been published on traditional bullying in individuals with developmental disabilities. These studies have shown that (a) bullying occurs in adolescents with severe intellectual disability, whereby gender and level of communication skills were not related to bullying [11], (b) prevalence of bullying is high in children with autism who are between 4-17 years old [12] and (c) bullying was relatively common in 186 students with intellectual disability who were between $12-21$ of age, whereby victimization was associated with high levels of emotional and interpersonal problems and bullies and victim/ bullies showed increased levels of challenging behaviours [13].

To date, no study on cyberbullying and related variables has been published in youth with developmental disabilities. This is surprising given that many of them use electronic communication tools. The aim of this study, therefore, is to investigate characteristics and frequency of cyberbullying in a sample of youth with intellectual disability and/or developmental disorders who are between 12-19 years old. This study assessed characteristics and frequency of cyberbullying in this target group and explored associations between characteristics and frequency of cyberbullying and other variables (e.g. gender, age, traditional bullying).

\section{Method}

\section{Participants and procedure}

Participants were youth with an intellectual disability and/or developmental disorders who were visiting the Herman Broeren School, a school for special education students in the southern province in the Netherlands. The school enrolled 280 students. Students were selected if they had a total IQ level of at least 50 and were able to read the information in the questionnaire. Students who did not have sufficient reading abilities were excluded. A sample of 150 students fulfilled the inclusion criteria. Parents were sent a letter asking permission. Parents of 30 children did not give their permission and these children were excluded. Several children were excluded because of illness or absence. All participants were familiar with cellphones, internet and/or computers.

A total of 114 students participated in this study, of whom most $(82 \%)$ had an intellectual disability or borderline IQ $(\mathrm{IQ}<85)$. IQ scores ranged from 52-118. Eighteen per cent of the participants had an average or above average IQ (total IQ between 85-118) and visited this school because of a developmental disorder and behaviour and emotional problems. Most adolescents (67\%) had a diagnosis, such as Attention Deficit Hyperactivity Disorder and Pervasive Developmental Disorder among others. Most (i.e. 97\%) students were born in The Netherlands. Participants were between 1219 years old and there were more boys $(72 \%)$ than girls $(28 \%)$. Selection criteria was a total IQ of at least 50 because a certain reading level was required to complete the questionnaire (see below).

Questionnaires (see Instrument) were completed in the students' classroom. During completion both the investigator and teacher were present in the classroom and students were informed about the 
topic of cyberbullying. They were told that the data would be assessed anonymously. Demographic information of each student was retrieved from his or her personal file.

\section{Questionnaire}

The questionnaire consisted of four parts. Each part contained several questions (open ended and closed). Questions and response options had been simplified by using language that the students were able to understand.

- Part 1 . The first part addressed sociodemographic variables (e.g. gender, age, IQ).

- Part 2. The second part contained nine questions measuring self-esteem (e.g. 'I think positively about myself', 'I am not good at anything'). These questions were derived from the questionnaire developed by Scholte et al. [14]. Each item could be rated on a 3-point Likert-type scale, with options 'true', 'sometimes true' and 'not true'. A mean item score of self-esteem was calculated, provided that six of the nine questions were scored.

- Part 3. This part contained questions on 12 depressive symptoms (e.g. 'I feel happy', 'I am tense and nervous', 'I worry about things'). Each item could be rated on a 3-point Likert scale, with options '(almost) never' (1), 'ometimes' (2) and 'often' (3). A mean item score was calculated provided that eight of the 12 questions had been endorsed by a student.

- Part 4. The fifth and largest part of the questionnaire contained questions about the use of cellphones and internet and bullying via these media. Items address type and frequency of bullying and victimization via internet and cellphone and are rated on a 5-point Likert-type scale: 'never' (1), 'once to five times' (2), 'once a month' (3), 'once a week' (4) and 'more times a week' (5). The items were scored for the last 3 months. A mean item score was calculated provided that four of the six questions had been scored by the respondents.

\section{Bullies, victims, bullies/victims and uninvolved students}

For the purpose of these analyses related to cyberbullying via internet and cyberbullying via cellphone, this study distinguished between four groups of students: the first group consisted only of victims, the second group comprised only students who bullied, the third group consisted of students who were both bully and victim and the fourth group consisted of students who were neither a bully nor a victim. The last group consisted of students who were uninvolved, thus neither a bully nor a victim of cyberbullying. These groups were established on the basis of deviation of scores. Students were allocated to groups if they had at least a score of ' 3 ' (occurring once a month) for being a victim, bully, bully/victim and uninvolved.

\section{Results \\ Cellphone}

Most students (i.e. 87\%) owned a cellphone and most popular activities via cellphone were to make phone calls $(70 \%)$ and send text messages (57\%). In a minority of students (i.e. $12 \%$ ), parents controlled their activities on the cellphone. Table I depicts percentages who were victimized or bullied via their cellphone at least once during the last 3 months. The most frequent types of cyberbullying were deliberately ignoring phone calls, frequent calling (or being called) and sending (or receiving) anonymous text messages. It appears that boys more often were involved in victimization and bullying via cellphone than girls (Table I).

\section{Internet}

Almost all students had access to the internet at home $(97 \%)$. Less than half of the sample $(41 \%)$ had a computer in their own bedroom. According to students, $69 \%$ reported that their parents were unaware of the type of activities they engaged in when using the internet. Most students used the internet for Microsoft Network (MSN) (67\%), downloading music (65\%) and playing online games $(57 \%)$, sending/receiving email (43\%), downloading pictures and films (31\%), looking for information for educational purposes $(30 \%)$, using a web cam $(28 \%)$, putting information about oneself on the internet $(27 \%)$, chatting on a website $(24 \%)$ and using skype (internet phone) (12\%). Cyberbullying occurred less often and took the form of putting information about other students on the internet $(5 \%)$, sending anonymous mails (4\%), hacking someone's computer $(4 \%)$ and sending a text message bomb via MSN (3\%).

Results depicted in Table II show that most students never bullied or were victimized via the internet during the last month. Percentages of students who were victimized at least once a week varied between $5-12 \%$, depending on the form of victimization. Percentages of students who bullied at least once a week were somewhat lower and varied between $1-8 \%$.

Prevalence of victims, bullies, victim/bullies and non-involved students

Most students were not involved in bullying via the internet (i.e. 90\%) and via cellphone (i.e. 86\%). 
Table I. Percentages of victims and bullies via cellphones for boys and girls.

\begin{tabular}{|c|c|c|c|c|c|c|}
\hline \multirow[b]{2}{*}{ Bullying via cellphone } & \multicolumn{3}{|c|}{ Victim } & \multicolumn{3}{|c|}{ Bully } \\
\hline & Boys & Girls & Total & Boys & Girls & Total \\
\hline Anonymous text message & $9(8 \%)$ & $1(1 \%)$ & $10(9 \%)$ & $7(6 \%)$ & $2(2 \%)$ & $9(8 \%)$ \\
\hline Bullying via textmessage & $3(3 \%)$ & $0(0 \%)$ & $3(3 \%)$ & $5(4 \%)$ & $2(2 \%)$ & $7(6 \%)$ \\
\hline Sending photo's & $3(3 \%)$ & $2(2 \%)$ & $5(4 \%)$ & $0(0 \%)$ & $0(0 \%)$ & $0(0 \%)$ \\
\hline Sending films & $2(2 \%)$ & $0(0 \%)$ & $2(2 \%)$ & $2(2 \%)$ & $0(0 \%)$ & $2(2 \%)$ \\
\hline Sending a bomb of text messages & $4(4 \%)$ & $0(0 \%)$ & $4(4 \%)$ & $3(3 \%)$ & $0(0 \%)$ & $3(3 \%)$ \\
\hline Frequent calling & $12(11 \%)$ & $5(4 \%)$ & $17(15 \%)$ & $4(4 \%)$ & $2(2 \%)$ & $6(5 \%)$ \\
\hline Ignoring phonecalls & $13(11 \%)$ & $8(7 \%)$ & $21(18 \%)$ & $19(17 \%)$ & $7(6 \%)$ & $26(23 \%)$ \\
\hline
\end{tabular}

Table II. Experiences of students who were victimized or who bullied via the internet.

\begin{tabular}{lccccc}
\hline & \multicolumn{2}{c}{ Victim } & & \multicolumn{2}{c}{ Bully } \\
\cline { 2 - 3 } \cline { 5 - 5 } Experiences on the internet & $\begin{array}{c}\text { Occurred about } \\
\text { once a month }\end{array}$ & $\begin{array}{c}\text { Once or more } \\
\text { times a week }\end{array}$ & & $\begin{array}{c}\text { Occurred about } \\
\text { once a month }\end{array}$ & $\begin{array}{c}\text { Once or more } \\
\text { times a week }\end{array}$ \\
\hline Hurting & $19 \%$ & $5 \%$ & $6 \%$ & $4 \%$ \\
Harassing & $21 \%$ & $12 \%$ & & $14 \%$ & $1 \%$ \\
Insulting & $21 \%$ & $8 \%$ & & $13 \%$ & $2 \%$ \\
Name calling & $27 \%$ & $9 \%$ & $22 \%$ & $5 \%$ \\
Making fun of & $29 \%$ & $12 \%$ & $24 \%$ & $5 \%$ \\
Ignoring & $14 \%$ & & & $2 \%$ & $5 \%$ \\
\hline
\end{tabular}

Percentages of students who were victimized, who bullied and who were both bully and victim via the internet were 7, 0 and 3, respectively. Four per cent of students were victimized via cellphone, $4 \%$ were bullies and 5\% were both victimized and bullied via cellphone.

\section{Cyberbullying via cellphone and internet}

There was a significant and large positive correlation $(r=0.68, p<0.01)$ between being a victim of cyberbullying via the internet and being an online bully. This means that most online bullies were also victims of this form of cyberbullying. There also was a positive correlation between being a victim of cyberbullying via cellphone and being a bully via cellphone $(r=0.68, p<0.01)$. The more students were a victim of bullying via the cellphone, the more they were also a bully using a cellphone. It may be concluded that among this sample of special education students, there is a particular group of students who are both a cyberbully and a victim of cyberbullying.

\section{Associations between cyberbullying and other variables}

Age. No significant associations were found between cyberbullying via cellphone or the internet and age in years.
IQ. There was a significant positive relationship between bullying via the internet and total IQ $(r=0.25, p<0.01)$ and verbal IQ $(r=0.26$, $p<0.01)$. The higher students' IQ, the more often they bullied via the internet.

Gender. There were no significant differences in frequency in cyberbullying between boys and girls in terms of frequencies in which they were involved in bullying or were victimized via cellphone and the internet.

$A D H D$ and $A S D$. This study compared three groups on victimization and bullying via the internet and cellphone: (a) students with ADHD, (b) students with ASD and (c) control group. There were no significant differences between groups except for bullying via cellphone. Students with ADHD bullied more often via cellphone than students from the other groups, $\chi^{2}(2)=8.91$, $p<0.01$.

Self-esteem, depressive feelings. There was a negative correlation $(r=-0.35, p<0.01)$ between being a victim of internet bullying and self-esteem and a positive correlation $(r=0.37, p<0.01)$ between being a victim of internet bullying and depressive feelings. That is, the more often a student was victimized via the internet the less self-esteem and 
the more depressive feelings $\mathrm{s} / \mathrm{he}$ reported. A positive correlation $(r=0.29, p<0.01)$ was also found between bullying and depressive feelings: the more a students bullied via the internet the more depressive feelings they reported. Next, a negative correlation was found between victimization via cellphone and self-esteem. The more often a student reported to be victimized via a cellphone the lower his of her level of self-esteem $(r=-0.31, p<0.01)$ and the higher his self-reported level of depressive feelings $(r=0.19, p<0.05)$. Finally, a negative correlation was found between bullying via cellphone and level of self-esteem $(r=-0.19, p<0.05)$ : the more students bullied via a cellphone, the lower their level of self-esteem. These results clearly indicate that there is a relationship between cyberbullying and emotional distress and psychological problems.

Frequency of use of computer. Results from MannWhitney tests revealed that there was an association between frequency with which students used the computer and cyberbullying. Students who used their computer for less than 1 hour each day were less often victimized via the internet than students who used the computer for more than 1 hour per day, $z=3.30, p<0.001$. Also, students who used their computer for more than 1 hour per day bullied more often via the internet than students who used their computer for less hours per day, $z=-3.06$, $p<0.001$. So the duration of computer usage may be seen as a risk factor for being victimized and/or bullying via the internet.

\section{Discussion}

The present study investigated prevalence and associated features of cyberbullying among 114 students with developmental disabilities who visited a school for special education. Results showed that victimization and bullying via the internet and cellphone was relatively prevalent and cyberbullying was related to IQ, presence of ADHD, self-esteem, depressive feelings and frequency of computer use. As far as is known, this is the first study on cyberbullying via electronic tools such as the internet and cellphones.

Percentages of students who were a cyberbully via cellphone varied between $0-26$, depending on the type of cyberbullying. The most frequent types of cyberbullying were deliberately ignoring phone calls, frequent calling (or being called) and sending (or receiving) anonymous text messages. These results are more or less comparable with those found in other studies among non-disabled youth who visit a regular school. For example, Smith et al. [6] report that bullying through phone calls and text messages were most common by students who visit regular schools. Concerning cyberbullying via the internet, this study found that $16 \%$ of the students had bullied at least once a month and $4 \%$ bullied once or more times a week. Victimization via the internet occurred once month for $22 \%$ of students and once or more times a week for $9 \%$ of students. Somewhat higher prevalence rates were reported in other studies. For example, in a Dutch study by Van den Eijnden et al. [7] it was found that $30-35 \%$ of students between 11-15 years old had been insulted, troubled or treated rudely on the internet at least once a month and $15-20 \%$ had been victimized via the internet. Differences in outcomes between this study and other studies $[6,8]$ may be explained by the lower IQ range of students in this sample. One may conclude that, in general, students with developmental disabilities have a somewhat lower probability to become victimized and/or bully via the internet and cellphone than their peers, although the lack of comparative studies preclude any firm conclusions.

This study found that most online bullies were also online victims. This relationship has also been found in a study by Li [15], where by far most (85\%) cyberbullies were also victimized via the internet. Thus, there seems to exist a sub-group of students who are both victim and bully. It is not yet clear in which ways this group of students differ from other studies in terms of sociodemographic characteristics.

This study found significant associations between cyberbullying and IQ, type of disorder (ADHD, ASD), self-esteem and depressive feelings and frequency of computer use. The finding that there is a relationship between emotional and psychological problems and victimization is in agreement with other studies on bullying. For example, Van de Eijnden et al. [7] found that online victims report significant more psychological problems (e.g. depressive feelings, loneliness, negative self-concept) than other youth between 11-15 years of age. Also, Reiter and Lapidot-Lefler [13] found that victims reported much higher levels of emotional and interpersonal problems than bullies and victim/ bullies.

A relationship wa also found between frequency of computer use and cyberbullying. This relationship has also been found by Ybarra and Mitchel [9] where online harassment was positively related to internet usage. Also, $\mathrm{Li}$ [15] reported that cyberbullies and cybervictims use the computer much more often than uninvolved students.

Several limitations of the present study should be mentioned. First, the lack of a control group precludes any conclusions on the specificity of these findings in a sample of students with developmental disabilities. Secondly, the validity of these 
conclusions remains unknown as it is not known if students' responses reflect their actual behaviours. Their responses were not compared to those of, for example, parents and teachers. Also, it is not clear if these findings may be generalized to the population of students visiting schools for special education. Finally, due to the fact that most data in these analyses were not normally distributed, mostly nonparametric tests were used.

Dealing with (cyber) bullying in a school for students with developmental disabilities may be difficult. An approach is needed in which students, teachers and parents work together [16-18]. Teachers should become more aware about the issue of bullying via electronic tools in students with developmental disabilities. It appears that students with developmental disabilities use such tools to the same extent as their non-disabled peers. Programmes should be developed for the identification, remediation and prevention of cyberbullying in special education schools. It appears that especially these students are in need of specific programmes with which they are being taught how to deal with the internet and other electronic tools. It is important for schools to have a model of legal issues relating to cyberbullying and its impact on student safety and learning in the school context [16, 17]. Finally, parents may be advised to exert more control over their children's activities on the internet and cellphone, to monitor their child's activities and at the same time provide them with information on how to use these tools.

\section{Acknowledgement}

We thank the Herman Broeren school for their participation.

Declaration of interest: The authors report no conflicts of interest. The authors alone are responsible for the content and writing of the paper.

\section{References}

1. Olweus D. Bullying at school. What we know and what we can do. Oxford: Blackwell; 1993.

2. Scholte RHJ, Overbeek G, Ten Brink G. Engels RCME, De Kemp RAT. Slachtoffers van pesten en hun vrienden: een onderzoek naar de vriendschapsprotectiehypothese (Victims of bullying and their friends: A study on the friendship protection hypothesis). Tijdschrift voor Orthopedagogiek (Journal of Special Education) 2006;45:452-463.

3. Raskauskas J, Stoltz AD. Involvement in traditional and electronic bullying among adolescents. Developmental Psychology 2007;43:564-575.

4. Williams KR, Guerra NG. Prevalence and predictors of internet bullying. Journal of Adolescent Health 2007; 41:14-21.

5. Carlson EJ, Crow Flannery $M$, Steinbring Kral $M$. Differences in bully/victim problems between early adolescents with learning disabilities and their non-disabled peers. ERIC Document Reproduction Service No. ED490374.

6. Smith P, Mahdavi J, Carvalhoho M, Tippett N. An investigation into cyberbullying, its forms, awareness and impact, and the relationship between age and gender in cyberbullying. Unit for school and family studies, Goldsmiths College, University of London; 2006.

7. Van den Eijnden R, Vermulst A, Van Rooy T, Meerkerk G. Pesten op internet en het psychosociale welbevinden van jongeren. Bullying on internet and psychosocial well-being of youth. Rotterdam: IVO, Rotterdam; 2006.

8. TNS-NIPO. Digitaal pesten. Cyberbullying. Amsterdam: TNS-NIPO; 2006.

9. Ybarra ML, Mitchell KJ. Youth engaging in online harassment: Associations with caregiver-child relationship. Journal of Adolescence 2004;27:319-336.

10. Delver B, Hop L. Pesten is laf! Cyberpesten is laffer. (Bullying is cowardly! Cyberbullying is more cowardly.) Haarlem: Vives Media; 2007.

11. Sheard C, Clegg J, Standen P, Cromby J. Bullying and people with severe intellectual disability. Journal of Intellectual Disability Research 2001;45:407-415.

12. Montes G, Halterman JS. Bullying among children with autism and the influence of comorbidity with ADHD: A population-based study. Ambulatory Pediatrics 2007; $7: 253-257$.

13. Reiter S, Lapidot-Lefler N. Bullying among special education students with intellectual disabilities: Differences in social adjustment and social skills. Intellectual and Developmental Disabilities 2007;45:174-181.

14. Scholte RHJ, Overbeek G, Ten Brink G, Rommes E, De Kemp R, Goossens L, Engels RCME. The significance of reciprocal and unilateral friendships for peer victimization in adolescence. Journal of Youth and Adolescence 2009;38: 89-100.

15. Li Q. Cyberbullying in schools: Nature and extent of Canadian adolescents' experience. 2005. Unpublished.

16. Shariff S. Cyberbullying. Issues and solutions for the school, the classroom and the home. London: Routledge; 2008.

17. Bak L, Dekker J, Van Drunen J, Groen N, Tempelman H. Scholen, ouders en hulpverlening op 1 lijn in de aanpak van digitaal pesten. (Schools, parents and professionals united in their approach of cyberbullying). Zwolle: Gereformeerde Hogeschool; 2007.

18. Agatston PW, Kowalski R, Limber S. Students' perspectives on cyberbullying. Journal of Adolescent Health 2007;41:59-60. 
Copyright of Developmental Neurorehabilitation is the property of Taylor \& Francis Ltd and its content may not be copied or emailed to multiple sites or posted to a listserv without the copyright holder's express written permission. However, users may print, download, or email articles for individual use. 